\title{
Impact of CMR parameters on prognosis after ST-elevation myocardial infarction - a comparison to traditional outcome markers
}

\author{
Suzanne de Waha ${ }^{1 *}$, Ingo Eitel', Steffen Desch', Georg Fuernau', Philipp Lurz', Matthias Gutberlet², \\ Gerhard Schuler ${ }^{1}$, Holger Thiele ${ }^{1}$
}

From 15th Annual SCMR Scientific Sessions

Orlando, FL, USA. 2-5 February 2012

\section{Summary}

In patients with STEMI, CMR parameters such as infarct size, MO and the MSI add incremental prognostic value above traditional outcome markers.

\section{Background}

Infarct size, microvascular obstruction (MO) and the myocardial salvage index (MSI) assessed by cardiac magnetic resonance imaging (CMR) have been shown to be associated with adverse clinical outcome. However, in daily clinical routine prognosis after STEMI is evaluated using simple assessable parameters such as ST-segment resolution, enzymatic infarct size, pre- and post-PCI TIMI-flow, left ventricular ejection fraction (LV EF) and TIMI-risk score. Up to date it remains unclear if the assessment of infarct size, MO and MSI by CMR adds incremental prognostic value in comparison to the traditional outcome markers.

\section{Methods}

STEMI patients reperfused by primary angioplasty $(n=392)$ within 12 hours after symptom onset underwent CMR 3 days after the index event (interquartile range [IQR] 2-4). Infarct size and MO were measured 15 min after gadolinium injection. T2-weighted and contrast-enhanced CMR was then used to calculate MSI. In all patients ST-resolution, pre- and post-PCI TIMI-flow, as well as the enzymatic infarct size using creatine kinase-MB were recorded. All patients underwent transthoracic echocardiography for the assessment of LV EF. Finally the TIMI-risk score was calculated.

'Department of Internal Medicine/Cardiology, University of Leipzig, Heart

Center, Leipzig, Germany

Full list of author information is available at the end of the article
Clinical follow-up was conducted after 19 months (IQR 10-27). The primary endpoint was defined as a composite of death, myocardial reinfarction and congestive heart failure. C-statistics were computed to assess the prognostic value of different models regarding the occurrence of the primary endpoint.

\section{Results}

Comparison of a model including only traditional outcome markers (model 1: ST-resolution, enzymatic infarct size, pre- and post-PCI TIMI-flow, LV EF and TIMI-risk score) to a model including only CMR parameters (model 2: infarct size, MO and MSI) revealed an increase of the corresponding c-statistics (model 1: 0.68 vs. model 2: $0.73, \mathrm{p}=0.03$ ). Comparison of model 1 to a model including the CMR parameters on top of traditional outcome markers (model 3) demonstrated an incremental prognostic value of infarct size, $\mathrm{MO}$ and MSI (model 1: 0.68 vs. model 3: $0.77, \mathrm{p}=0.02$ ).

\section{Conclusions}

In patients with STEMI, CMR parameters such as infarct size, MO and the MSI add incremental prognostic value above traditional outcome markers.

\section{Funding}

None.

\section{Author details}

'Department of Internal Medicine/Cardiology, University of Leipzig, Heart Center, Leipzig, Germany. ${ }^{2}$ Department of Diagnostic and Interventional Radiology, University of Leipzig, Heart Center, Leipzig, Germany.

Published: 1 February 2012

(c) 2012 de Waha et al; licensee BioMed Central Ltd. This is an open access article distributed under the terms of the Creative Commons Attribution License (http://creativecommons.org/licenses/by/2.0), which permits unrestricted use, distribution, and reproduction in any medium, provided the original work is properly cited. 
doi:10.1186/1532-429X-14-S1-O4

Cite this article as: de Waha et al:: Impact of CMR parameters on prognosis after ST-elevation myocardial infarction - a comparison to

traditional outcome markers. Journal of Cardiovascular Magnetic

Resonance 2012 14(Suppl 1):O4.

Submit your next manuscript to BioMed Central and take full advantage of:

- Convenient online submission

- Thorough peer review

- No space constraints or color figure charges

- Immediate publication on acceptance

- Inclusion in PubMed, CAS, Scopus and Google Scholar

- Research which is freely available for redistribution

Submit your manuscript at www.biomedcentral.com/submit

() BioMed Central 